\title{
Effect of low-frequency deep brain stimulation on sensory thresholds in Parkinson's disease
}

\author{
Abigail Belasen, BSc, ${ }^{1}$ Khizer Rizvi, BS, ${ }^{1}$ Lucy E. Gee, BS, ${ }^{1,2}$ Philip Yeung, BS, ${ }^{1}$ Julia Prusik, BS, ${ }^{1}$ \\ Adolfo Ramirez-Zamora, MD, ${ }^{3}$ Era Hanspal, MD, ${ }^{3}$ Priscilla Paiva, MD, ${ }^{3}$ Jennifer Durphy, MD, ${ }^{3}$ \\ Charles E. Argoff, MD, ${ }^{3}$ and Julie G. Pilitsis, MD, PhD ${ }^{1,2}$
}

Departments of ${ }^{1}$ Neurosurgery and ${ }^{3}$ Neurology, Albany Medical Center; and ${ }^{2}$ Center for Neuroscience and Neuropharmacology, Albany Medical College, Albany, New York

OBJECTIVE Chronic pain is a major distressing symptom of Parkinson's disease (PD) that is often undertreated. Subthalamic nucleus (STN) deep brain stimulation (DBS) delivers high-frequency stimulation (HFS) to patients with PD and has been effective in pain relief in a subset of these patients. However, up to $74 \%$ of patients develop new pain concerns while receiving STN DBS. Here the authors explore whether altering the frequency of STN DBS changes pain perception as measured through quantitative sensory testing (QST).

METHODS Using QST, the authors measured thermal and mechanical detection and pain thresholds in 19 patients undergoing DBS via HFS, low-frequency stimulation (LFS), and off conditions in a randomized order. Testing was performed in the region of the body with the most pain and in the lower back in patients without chronic pain.

RESULTS In the patients with chronic pain, LFS significantly reduced heat detection thresholds as compared with thresholds following HFS $(p=0.029)$ and in the off state $(p=0.010)$. Moreover, LFS resulted in increased detection thresholds for mechanical pressure $(p=0.020)$ and vibration $(p=0.040)$ compared with these thresholds following HFS. Neither LFS nor HFS led to changes in other mechanical thresholds. In patients without chronic pain, LFS significantly increased mechanical pain thresholds in response to the 40-g pinprick compared with thresholds following HFS $(p=$ 0.032).

CONCLUSIONS Recent literature has suggested that STN LFS can be useful in treating nonmotor symptoms of PD. Here the authors demonstrated that LFS modulates thermal and mechanical detection to a greater extent than HFS. Low-frequency stimulation is an innovative means of modulating chronic pain in PD patients receiving STN DBS. The authors suggest that STN LFS may be a future option to consider when treating Parkinson's patients in whom pain remains the predominant complaint.

http://thejns.org/doi/abs/10.3171/2016.2.JNS152231

KEY WORDS low-frequency stimulation; high-frequency stimulation; deep brain stimulation; quantitative sensory testing; mechanical detection thresholds; thermal thresholds; pressure pain thresholds; vibratory detection; chronic pain; functional neurosurgery

$\mathrm{C}$ HRONIC pain is a major nonmotor symptom of Parkinson's disease (PD). Approximately 40\%-85\% of patients with PD experience pain, 3,14,33,41,55 and in some patients the pain can overshadow the motor symptoms of the disease. ${ }^{44,57}$ Early after a PD diagnosis, dopaminergic medications may provide some analgesic efficacy; $; 2$ however, up to $49 \%$ of patients believe their medications do not reduce the severity of their pain. ${ }^{46} \mathrm{In}$ patients with more advanced disease, subthalamic nucleus (STN) deep brain stimulation (DBS), commonly used to treat the motor symptoms of PD, is gaining attention as an effective therapy for PD-related pain. Several studies have shown significant improvements in global pain scores 6 months to 1 year following DBS surgery, ${ }^{12,19,42,43,52}$ and a recent 8-year follow-up study suggests that preoperative pain can be well managed over time. ${ }^{29}$ Although STN

ABBREVIATIONS DBS = deep brain stimulation; HFS = high-frequency stimulation; LFS = low-frequency stimulation; PD = Parkinson disease; $Q S T$ = quantitative sensory testing; STN = subthalamic nucleus.

SUBMITTED September 22, 2015. ACCEPTED February 9, 2016.

INCLUDE WHEN CITING Published online April 22, 2016; DOI: 10.3171/2016.2.JNS152231. 
DBS has been shown to be superior to high-dose levodopa treatment in controlling chronic pain, ${ }^{54}$ the mechanism by which STN DBS improves pain remains unclear. Further, $74 \%$ of patients develop new-onset pain after STN DBS. ${ }^{8}$

Quantitative sensory testing (QST) provides an objective measure of pain perception through mechanical and thermal threshold assessment, which is used to clinically assess pain sensitivity and/or sensory dysfunction. ${ }^{1}$ The effects of STN DBS on sensory thresholds are varied, ${ }^{12,26,46,52}$ however, a study of 25 PD patients has suggested that high-frequency stimulation (HFS) increases mechanical and thermal pain thresholds. ${ }^{26,37,53}$ Moreover, a recent study in 6OHDA (6-hydroxydopamine)-lesioned rats has suggested that both HFS and low-frequency stimulation (LFS) of the STN increase mechanical and thermal thresholds. ${ }^{24}$ Thus, this work implies that pain may be modulated with LFS of the STN. Additionally, STN LFS has been shown to improve motor function in PD patients. ${ }^{30,38}$ We believe that LFS also provides an optional therapeutic strategy for alleviating pain in patients undergoing DBS. Here, we evaluate LFS delivered at $60 \mathrm{~Hz}$ and its effects on mechanical and thermal sensory and pain thresholds in PD patients with and without chronic pain.

\section{Methods \\ Participants}

Institutional review board approval was granted by $\mathrm{Al}-$ bany Medical College to conduct this study. All enrolled subjects had undergone STN implantation of a DBS device for the treatment of refractory motor fluctuations in PD. Those who qualified for surgical treatment had completed the Unified Parkinson's Disease Rating Scale (UPDRS) and neuropsychological testing as part of the routine preoperative workup. Patients who did not improve more than 30\% on the Core Assessment Program for Surgical Interventional Therapies (CAPSIT) on/off medication testing were not considered acceptable surgical candidates and neither were those who demonstrated dementia, significant cognitive impairment, or unstable psychiatric disease at baseline testing. From a database of patients who had undergone STN DBS, patients were selected for study participation regardless of their pain status. Chronic pain, defined as 8 weeks of pain despite treatment, was self-reported by the patient at the time of testing. Subjects who could not complete testing because of language barriers and/or dementia were excluded from the study. Informed consent was obtained from all study participants prior to testing.

\section{Outcome Measures}

All patients completed the visual analog scale, McGill Pain Questionnaire, Oswestry Disability Index, and Pain Catastrophizing Scale and provided their pain medication usage. Quantitative sensory testing was performed to assess detection and pain thresholds for mechanical and sensory stimuli. Testing was conducted at 3 stimulation settings: 1) the patient's optimized HFS settings for the treatment of motor symptoms, 2) LFS at $60 \mathrm{~Hz}$ with the same pulse width and voltage, and 3) off stimulation, with the order of testing randomized. Both patient and exam- iner were aware of the patient's stimulation setting during testing. A minimum of 10 minutes at the new setting was allotted in between each QST session. Testing was performed on the side of the body receiving therapeutic neuromodulation and at the site where the most pain was reported. If the patient did not report pain, QST was performed on the lower back given the high incidence of lowback pain in this population. ${ }^{8}$ Once an optimal spot for testing was determined, an " $\mathrm{x}$ " was drawn to ensure that all testing was performed on the same area.

Thresholds for mechanical sensation were detected using von Frey filaments, which allow forces between 0.25 and $512 \mathrm{mN}$ to be applied to the skin with a consistent and uniform contact surface area and shape. Mechanical pain was detected using standardized 10- and 40-g weighted pinprick stimulators. Patients were asked to rate the pain felt after each 10- and 40-g pinprick on a scale of $0-10$, with 10 being the highest level of pain. Pressure pain was detected through a standard pressure gauge device allowing $1-10 \mathrm{~kg}$ of pressure to be applied. Patients were asked to notify the researcher when the pressure became uncomfortable. Vibration detection was assessed using a RydelSeiffer tuning fork. Using the Medoc Pathway thermode (device range $0^{\circ} \mathrm{C}-50^{\circ} \mathrm{C}$ ), we assessed cool and warm thermal detection and determined when the temperature became painful.

\section{Data Analysis}

For the demographic and medical information collected, statistical analysis was performed in SPSS (IBM SPSS Statistics for Windows, version 22.0, IBM Corp.) using paired t-tests and regression analysis to assess differences, in which $\mathrm{p}<0.05$ was considered significant.

\section{Results}

\section{Demographics}

Nineteen PD patients who had undergone surgery for STN DBS were included in this study. Thirteen patients had unilateral STN DBS surgery and 6 had bilateral surgery. Eleven patients reported chronic pain. Additional demographic information as well as the QST testing sites is listed in Table 1.

\section{Results of Sensory Threshold Testing}

Patients with chronic pain who received STN LFS had significantly reduced heat detection thresholds, compared with thresholds following HFS $(p=0.029)$ or in the off state $(\mathrm{p}=0.010$; Fig. 1A). In addition, LFS significantly increased mechanical detection thresholds $(\mathrm{p}=0.020$; Fig. 1B) and vibration detection ( $p=0.040$; Fig. 1C) compared with thresholds following HFS. In patients without chronic pain, LFS significantly increased mechanical pain thresholds in response to the $40-\mathrm{g}$ pinprick as compared with HFS ( $p=0.032$; Fig. 1D). Combining all patients regardless of pain status, we found that LFS significantly reduced heat detection thresholds compared with HFS ( $\mathrm{p}$ $=0.044)$. The mean mechanical and thermal detection values and $\mathrm{p}$ values are listed in Table 2.

Using ordinary least-squares regression analysis, we evaluated each QST test on the 3 categorical factors (pa- 
TABLE 1. Demographic distribution of PD patients with and without chronic pain

\begin{tabular}{|c|c|c|c|c|}
\hline $\begin{array}{l}\text { Patient } \\
\text { No. }\end{array}$ & $\begin{array}{c}\text { Age (yrs) } \\
\text { Sex }\end{array}$ & $\begin{array}{l}\text { Yrs Since } \\
\text { Diagnosis }\end{array}$ & $\begin{array}{c}\text { Chronic } \\
\text { Pain }\end{array}$ & QST Testing Location \\
\hline 1 & $68, F$ & 15 & Yes & Lt dorsal medial hand \\
\hline 2 & $63, F$ & 7 & Yes & Lt low back \\
\hline 3 & $70, F$ & 20 & Yes & Lt low back \\
\hline 4 & $66, M$ & 7 & Yes & Lt posterior shoulder \\
\hline 5 & $55, M$ & 20 & Yes & Lt low back \\
\hline 6 & $71, \mathrm{~F}$ & 17 & Yes & Lt lat ankle \\
\hline 7 & $66, \mathrm{M}$ & 6 & Yes & Rt posterior shoulder \\
\hline 8 & $58, \mathrm{M}$ & 5 & Yes & Rt hip \\
\hline 9 & $61, \mathrm{M}$ & 11 & Yes & Rt dorsal thumb \\
\hline 10 & $50, M$ & 10 & Yes & Bilat epigastric region \\
\hline 11 & $43, F$ & 23 & Yes & Lt anterior chest \\
\hline 12 & $71, F$ & 71 & No & Lt low back \\
\hline 13 & $75, F$ & 75 & No & Lt low back \\
\hline 14 & $36, \mathrm{M}$ & 36 & No & Bilat low back \\
\hline 15 & $72, \mathrm{M}$ & 72 & No & Bilat low back \\
\hline 16 & $67, F$ & 67 & No & Bilat low back \\
\hline 17 & $57, \mathrm{M}$ & 57 & No & Bilat low back \\
\hline 18 & $79, \mathrm{M}$ & 79 & No & Lt low back \\
\hline 19 & $68, M$ & 68 & No & Bilat low back \\
\hline
\end{tabular}

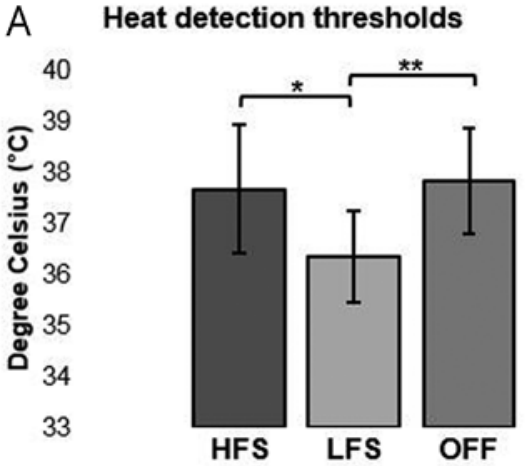

C Vibration detection thresholds
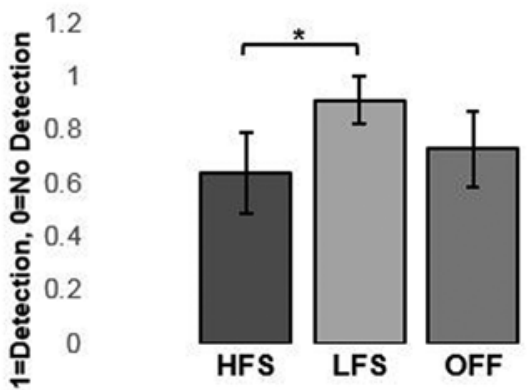

tient sex, pain status, and testing site) for significance. At the 5\% level of significance, there was a statistically significant difference between male and female patients receiving HFS or LFS for both the pressure pain and 40-g pinprick tests. Specifically, women were more sensitive to pressure pain and less sensitive to mechanical pain. We also found a significant difference between testing the lower back and other sites for patients receiving HFS or LFS for the 10-g Neuropen test and for patients receiving HFS for the 40-g Neuropen test. The lower back was less sensitive. Results are summarized in Table 3.

\section{Discussion}

In this study, we demonstrated that LFS, as compared with traditional HFS, can differentially alter sensory thresholds for specific sensory modalities. Low-frequency stimulation significantly reduced heat detection thresholds, regardless of patient pain status. However, when patients were analyzed by pain status, LFS had different effects, suggesting that pain status may play an important role in the mechanism underlying low-frequency DBS symptom relief. Although chronic pain patients receiving LFS were less sensitive to mechanical and vibrational stimuli, they were more sensitive to heat. In contrast, patients without chronic pain who received LFS showed increased tolerance for mechanical pain, allowing this subset of patients to potentially exhibit greater pain relief than without the stimulator.

Mechanical and thermal detection thresholds were generally independent of patient sex; however, a stark differ-

\section{B Mechanical detection thresholds}
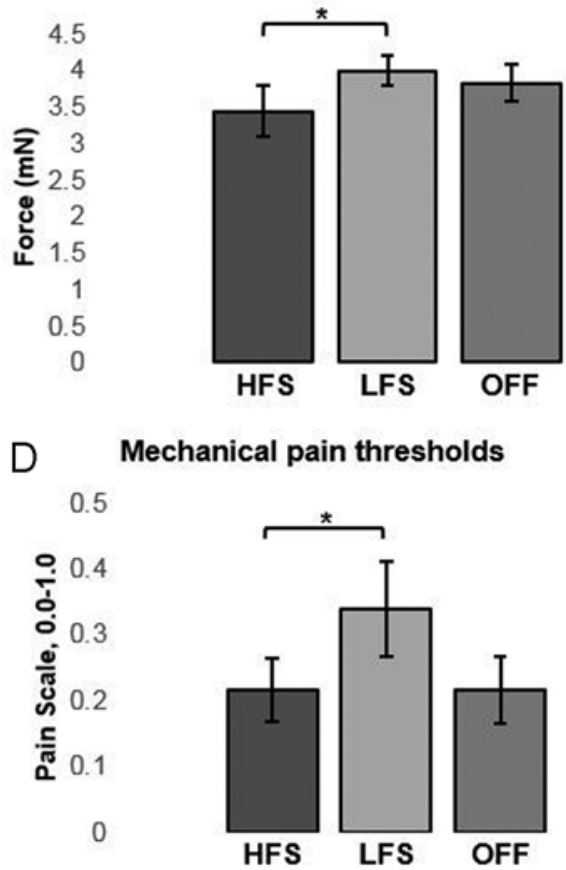

FIG. 1. In PD patients with chronic pain, LFS significantly reduced heat detection thresholds (A) compared with HFS $(p=0.029)$ or no stimulation $(p=0.010)$, LFS increased mechanical detection thresholds $(B)$ compared with HFS $(p=0.020)$, and LFS increased vibration detection $(C)$ compared with HFS $(p=0.040)$. In PD patients without chronic pain, LFS significantly increased mechanical pain thresholds (D) compared with HFS ( $p=0.032)$. 


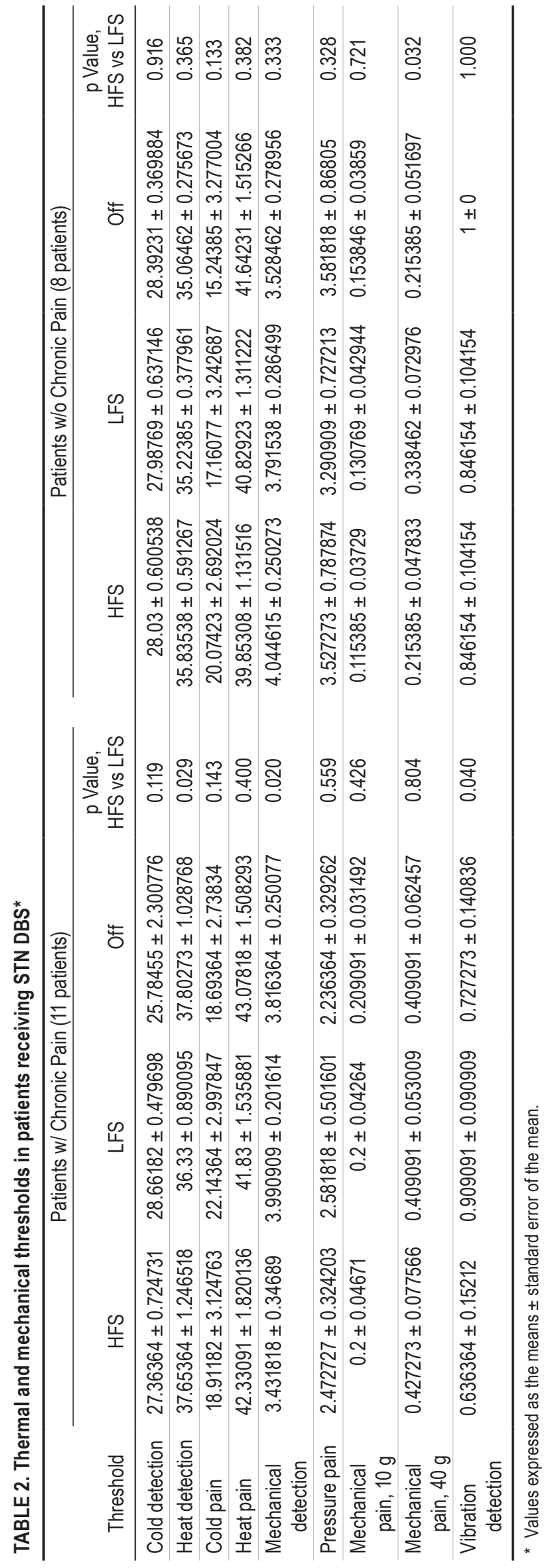

TABLE 3. Regression analyses $p$ values for each QST test on patient sex, pain status, and testing site

\begin{tabular}{|c|c|c|c|c|}
\hline Test & Frequency & $\begin{array}{c}\text { Patient } \\
\text { Sex }\end{array}$ & $\begin{array}{l}\text { Pain } \\
\text { Status }\end{array}$ & $\begin{array}{c}\text { Testing } \\
\text { Site }\end{array}$ \\
\hline \multirow[t]{2}{*}{ Cold detection } & HFS & 0.265 & 0.684 & 0.726 \\
\hline & LFS & 0.742 & 0.148 & 0.293 \\
\hline \multirow[t]{2}{*}{ Heat detection } & HFS & 0.267 & 0.964 & 0.152 \\
\hline & LFS & 0.208 & 0.690 & 0.071 \\
\hline \multirow[t]{2}{*}{ Cold pain } & HFS & 0.080 & 0.441 & 0.142 \\
\hline & LFS & 0.168 & 0.070 & 0.160 \\
\hline \multirow[t]{2}{*}{ Heat pain } & HFS & 0.372 & 0.850 & 0.103 \\
\hline & LFS & 0.405 & 0.502 & 0.128 \\
\hline \multirow[t]{2}{*}{ Mechanical detection } & HFS & 0.245 & 0.956 & 0.118 \\
\hline & LFS & 0.850 & 0.391 & 0.569 \\
\hline \multirow[t]{2}{*}{ Pressure pain } & HFS & 0.024 & 0.666 & 0.069 \\
\hline & LFS & 0.011 & 0.456 & 0.064 \\
\hline \multirow[t]{2}{*}{ Mechanical pain, $10 \mathrm{~g}$} & HFS & 0.433 & 0.464 & 0.031 \\
\hline & LFS & 0.402 & 0.395 & 0.0392 \\
\hline \multirow[t]{2}{*}{ Mechanical pain, $40 \mathrm{~g}$} & HFS & 0.002 & 0.088 & 0.000 \\
\hline & LFS & 0.030 & 0.332 & 0.101 \\
\hline \multirow[t]{2}{*}{ Vibration detection } & HFS & 0.692 & 0.907 & 0.314 \\
\hline & LFS & 0.652 & 0.550 & 0.956 \\
\hline
\end{tabular}

ence between men and women appeared to persist across stimulation settings for both pressure pain and mechanical pain with the 40-g pinprick. According to our results, men appeared to have a higher threshold for pressure pain than women for both HFS and LFS. On the other hand, women had a higher threshold for mechanical pain with the $40-\mathrm{g}$ pinprick. Current literature has mixed results regarding sex differences in pain sensitivity. Some studies suggest that women have a less efficient pain inhibition capacity than men, ${ }^{23,27,28}$ while other studies report no change. . $^{2,22,35}$ One study suggests that behavioral and psychological factors may influence the perception of pain differently among men and women. ${ }^{10}$

Quantitative sensory testing location only had an influence on the 10-g and 40-g mechanical pain pinprick tests. According to our results, the lower back is less sensitive to mechanical pain. However, the correlation (r) between the patient's report of chronic pain and using the lower back as a testing site was -0.678 , which indicates a strong relationship between patients without pain and less sensitivity in the lower back. This finding indicated that the lower-back test site may have influenced the results of these tests.

Little evidence exists for the efficacy of other common chronic pain treatments such as antiepileptics (for example, gabapentin, pregabalin), antispasmodics (for example, baclofen), antidepressants, or opioids for the treatment of PD-related chronic pain. However, in 2007, Djaldetti et al. did provide some evidence of pain relief after 6 weeks of duloxetine (serotonin-norepinephrine reuptake inhibitor) treatment in PD patients. ${ }^{18}$ Interestingly, the efficacy of STN DBS for the treatment of different types of pain is still debated. For example, in a cohort of 41 patients, significant improvements in dystonic and musculoskeletal 
pain occurred at 1 year, while neuropathic and central pain remained unchanged..$^{13}$ In another study, dystonic and central pain were relieved, while musculoskeletal and radicular pain were not. ${ }^{32}$

Extensive evidence suggests that a variety of sensory functions are altered in PD, and recent studies have shown that patients and animal models exhibit lower mechani$\mathrm{cal}^{42,46,48,60}$ and thermal ${ }^{21,42,46,48}$ thresholds than those in healthy controls. Unfortunately, treatment for PD-related pain is particularly difficult as it can manifest in a variety of ways (musculoskeletal, dystonic, radiculoneuritic, or central) and patients can suffer from pain from different origins at the same time. ${ }^{20}$ Given that pain in PD is under-recognized, undertreated, and understudied, there is a critical need to develop new therapies in patients whose pain is refractory to dopaminergic medications or traditional STN HFS. Traditional STN DBS is delivered at a high frequency typically ranging from 130 to 185 Hz. ${ }^{51}$ However, recent literature has demonstrated the efficacy of STN LFS in improving motor function in PD patients. $., 30,38,39,45,47,58$

Our data are novel in showing that LFS can be used as an optional therapeutic strategy for pain relief in PD patients undergoing DBS. In addition, given our results, there could be a relationship between chronic pain in DBS and specific sensory threshold modalities. Among patients receiving STN DBS, mechanical pain changes were evident in those without pain, whereas thermal and mechanical changes were evident in those with pain. It is uncertain whether LFS is more sensitive to specific sensory modalities depending on whether or not there is chronic pain. However, our analysis suggests there may be some connection.

We acknowledge that QST has limitations. Its results may be subject to patient behavior, including boredom, distraction, or mental fatigue..$^{50}$ Although QST results have been shown to be reproducible over a period of weeks for healthy subjects, ${ }^{50}$ we performed testing at a single visit. Moreover, we performed mechanical testing only once but thermal testing twice to minimize patient confusion when conducting these tests. In addition, the participants' selfassessments on their areas of chronic pain are subjective since their levels of current pain often change from day to day. This could cause a bias on their level of response to QST and stimulation setting changes. Moreover, neither patients nor examiners were blinded to the stimulation settings during testing. Changing the stimulation settings can have a profound effect on patient motor symptoms, and patients often felt when their stimulator settings were adjusted. We acknowledge this as a potential limitation of the study.

We examined alterations in sensory thresholds following acute LFS in PD patients with and without complaints of chronic pain. We did not address whether these patients would report changes in chronic pain since they were only stimulated with LFS for 15 minutes. However, sensory thresholds have been used as quantitative measures of changes in sensory processing in other studies and suggest changes in pain states. . $^{5,16,17,25,34,40,49,59}$ Although the analgesic effects of STN DBS in PD are not well understood, the current literature suggests that STN DBS alters sensory processing in the central nervous system, including the basal ganglia, ${ }^{11,31,49}$ through increased pain thresholds. ${ }^{12,15,36}$ Since dopamine can also modify pain perception through increased pain thresholds in $\mathrm{PD}^{6,25,36}$ and levodopa dosing is typically reduced following STN DBS, it is conceivable that STN DBS modulates neurotransmission in midbrain circuits that are altered in PD.

\section{Conclusions}

In summary, although traditional STN HFS has proven efficacy in treating the motor symptoms of $\mathrm{PD}^{4}$ patients can develop new pain symptoms or continue to have chronic pain. ${ }^{56}$ Given the changes in sensory detection and pain thresholds in our patient cohort, we suggest that STN LFS may be a future option to consider in the treatment of PD-related pain refractory to other therapies. Further studies should address whether long-term STN LFS improves chronic pain status in these patients. In addition, patients receiving STN DBS who have a history of chronic pain may respond differently to specific mechanical and thermal stimuli compared with those who do not have chronic pain. Tailoring stimulation parameters to address specific symptoms of PD is critical for the optimization of DBS therapy.

\section{Acknowledgments}

The Phyllis E. Dake Endowed Chair in Movement Disorders (J.G.P. and A.R.Z.) supported this study. We thank our colleague, Damian Shin, $\mathrm{PhD}$, for providing his insight and expertise to greatly improve the quality of this paper.

\section{References}

1. Arendt-Nielsen L, Yarnitsky D: Experimental and clinical applications of quantitative sensory testing applied to skin, muscles and viscera. J Pain 10:556-572, 2009

2. Baad-Hansen L, Poulsen HF, Jensen HM, Svensson P: Lack of sex differences in modulation of experimental intraoral pain by diffuse noxious inhibitory controls (DNIC). Pain 116:359-365, 2005

3. Beiske AG, Loge JH, Rønningen A, Svensson E: Pain in Parkinson's disease: prevalence and characteristics. Pain 141:173-177, 2009

4. Benabid AL, Chabardes S, Mitrofanis J, Pollak P: Deep brain stimulation of the subthalamic nucleus for the treatment of Parkinson's disease. Lancet Neurol 8:67-81, 2009

5. Bouhassira D, Attal N, Alchaar H, Boureau F, Brochet B, Bruxelle J, et al: Comparison of pain syndromes associated with nervous or somatic lesions and development of a new neuropathic pain diagnostic questionnaire (DN4). Pain 114:29-36, 2005

6. Brefel-Courbon C, Ory-Magne F, Thalamas C, Payoux P, Rascol O: Nociceptive brain activation in patients with neuropathic pain related to Parkinson's disease. Parkinsonism Relat Disord 19:548-552, 2013

7. Brefel-Courbon C, Payoux P, Thalamas C, Ory F, Quelven I, Chollet F, et al: Effect of levodopa on pain threshold in Parkinson's disease: a clinical and positron emission tomography study. Mov Disord 20:1557-1563, 2005

8. Broetz D, Eichner M, Gasser T, Weller M, Steinbach JP: Radicular and nonradicular back pain in Parkinson's disease: a controlled study. Mov Disord 22:853-856, 2007

9. Brozova H, Barnaure I, Alterman RL, Tagliati M: STN-DBS frequency effects on freezing of gait in advanced Parkinson disease. Neurology 72:770-771, 2009 
10. Bulls HW, Freeman EL, Anderson AJ, Robbins MT, Ness TJ, Goodin BR: Sex differences in experimental measures of pain sensitivity and endogenous pain inhibition. J Pain Res 8:311-320, 2015

11. Chudler EH, Dong WK: The role of the basal ganglia in nociception and pain. Pain 60:3-38, 1995

12. Ciampi de Andrade D, Lefaucheur JP, Galhardoni R, Ferreira KS, Brandão Paiva AR, Bor-Seng-Shu E, et al: Subthalamic deep brain stimulation modulates small fiber-dependent sensory thresholds in Parkinson's disease. Pain 153:1107-1113, 2012

13. Cury RG, Galhardoni R, Fonoff ET, Dos Santos Ghilardi MG, Fonoff F, Arnaut D, et al: Effects of deep brain stimulation on pain and other nonmotor symptoms in Parkinson disease. Neurology 83:1403-1409, 2014

14. Defazio G, Berardelli A, Fabbrini G, Martino D, Fincati E, Fiaschi A, et al: Pain as a nonmotor symptom of Parkinson disease: evidence from a case-control study. Arch Neurol 65:1191-1194, 2008

15. Dellapina E, Ory-Magne F, Regragui W, Thalamas C, Lazorthes Y, Rascol O, et al: Effect of subthalamic deep brain stimulation on pain in Parkinson's disease. Pain 153:22672273, 2012

16. Derbyshire SW, Jones AK, Creed F, Starz T, Meltzer CC, Townsend DW, et al: Cerebral responses to noxious thermal stimulation in chronic low back pain patients and normal controls. Neuroimage 16:158-168, 2002

17. Djaldetti R, Shifrin A, Rogowski Z, Sprecher E, Melamed E, Yarnitsky D: Quantitative measurement of pain sensation in patients with Parkinson disease. Neurology 62:2171-2175, 2004

18. Djaldetti R, Yust-Katz S, Kolianov V, Melamed E, Dabby R: The effect of duloxetine on primary pain symptoms in Parkinson disease. Clin Neuropharmacol 30:201-205, 2007

19. Drake DF, Harkins S, Qutubuddin A: Pain in Parkinson's disease: pathology to treatment, medication to deep brain stimulation. NeuroRehabilitation 20:335-341, 2005

20. Fil A, Cano-de-la-Cuerda R, Muñoz-Hellín E, Vela L, Ramiro-González M, Fernández-de-Las-Peñas C: Pain in Parkinson disease: a review of the literature. Parkinsonism Relat Disord 19:285-294, 2013

21. Ford B: Pain in Parkinson's disease. Mov Disord 25 (Suppl 1):S98-S103, 2010

22. France CR, Suchowiecki S: A comparison of diffuse noxious inhibitory controls in men and women. Pain 81:77-84, 1999

23. Ge HY, Madeleine P, Arendt-Nielsen L: Sex differences in temporal characteristics of descending inhibitory control: an evaluation using repeated bilateral experimental induction of muscle pain. Pain 110:72-78, 2004

24. Gee LE, Chen N, Ramirez-Zamora A, Shin DS, Pilitsis JG: The effects of subthalamic deep brain stimulation on mechanical and thermal thresholds in 6OHDA-lesioned rats. Eur J Neurosci 42:2061-2069, 2015

25. Gerdelat-Mas A, Simonetta-Moreau M, Thalamas C, OryMagne F, Slaoui T, Rascol O, et al: Levodopa raises objective pain threshold in Parkinson's disease: a RIII reflex study. J Neurol Neurosurg Psychiatry 78:1140-1142, 2007

26. Gierthmühlen J, Arning P, Binder A, Herzog J, Deuschl G, Wasner G, et al: Influence of deep brain stimulation and levodopa on sensory signs in Parkinson's disease. Mov Disord 25:1195-1202, 2010

27. Goodin BR, McGuire L, Allshouse M, Stapleton L, Haythornthwaite JA, Burns N, et al: Associations between catastrophizing and endogenous pain-inhibitory processes: sex differences. J Pain 10:180-190, 2009

28. Granot M, Weissman-Fogel I, Crispel Y, Pud D, Granovsky Y, Sprecher E, et al: Determinants of endogenous analgesia magnitude in a diffuse noxious inhibitory control (DNIC) paradigm: do conditioning stimulus painfulness, gender and personality variables matter? Pain 136:142-149, 2008
29. Jung YJ, Kim HJ, Jeon BS, Park H, Lee WW, Paek SH: An 8-year follow-up on the effect of subthalamic nucleus deep brain stimulation on pain in Parkinson disease. JAMA Neurol 72:504-510, 2015

30. Khoo HM, Kishima H, Hosomi K, Maruo T, Tani N, Oshino $\mathrm{S}$, et al: Low-frequency subthalamic nucleus stimulation in Parkinson's disease: a randomized clinical trial. Mov Disord 29:270-274, 2014

31. Kim HJ, Jeon BS, Paek SH: Effect of deep brain stimulation on pain in Parkinson disease. J Neurol Sci 310:251-255, 2011

32. Kim HJ, Paek SH, Kim JY, Lee JY, Lim YH, Kim MR, et al: Chronic subthalamic deep brain stimulation improves pain in Parkinson disease. J Neurol 255:1889-1894, 2008

33. Lee MA, Walker RW, Hildreth TJ, Prentice WM: A survey of pain in idiopathic Parkinson's disease. J Pain Symptom Manage 32:462-469, 2006

34. Lim SY, Farrell MJ, Gibson SJ, Helme RD, Lang AE, Evans AH: Do dyskinesia and pain share common pathophysiological mechanisms in Parkinson's disease? Mov Disord 23:1689-1695, 2008

35. Locke D, Gibson W, Moss P, Munyard K, Mamotte C, Wright A: Analysis of meaningful conditioned pain modulation effect in a pain-free adult population. J Pain 15:1190-1198, 2014

36. Marques A, Chassin O, Morand D, Pereira B, Debilly B, Derost P, et al: Central pain modulation after subthalamic nucleus stimulation: A crossover randomized trial. Neurology 81:633-640, 2013

37. Maruo T, Saitoh Y, Hosomi K, Kishima H, Shimokawa T, Hirata M, et al: Deep brain stimulation of the subthalamic nucleus improves temperature sensation in patients with Parkinson's disease. Pain 152:860-865, 2011

38. Moreau C, Defebvre L, Destée A, Bleuse S, Clement F, Blatt JL, et al: STN-DBS frequency effects on freezing of gait in advanced Parkinson disease. Neurology 71:80-84, 2008

39. Moreau C, Pennel-Ployart O, Pinto S, Plachez A, Annic A, Viallet F, et al: Modulation of dysarthropneumophonia by low-frequency STN DBS in advanced Parkinson's disease. Mov Disord 26:659-663, 2011

40. Mylius V, Engau I, Teepker M, Stiasny-Kolster K, Schepelmann K, Oertel WH, et al: Pain sensitivity and descending inhibition of pain in Parkinson's disease. J Neurol Neurosurg Psychiatry 80:24-28, 2009

41. Nègre-Pagès L, Regragui $W$, Bouhassira $D$, Grandjean $H$, Rascol O, Group DS: Chronic pain in Parkinson's disease: the cross-sectional French DoPaMiP survey. Mov Disord 23:1361-1369, 2008

42. Oshima H, Katayama Y, Morishita T, Sumi K, Otaka T, Kobayashi K, et al: Subthalamic nucleus stimulation for attenuation of pain related to Parkinson disease. J Neurosurg 116:99-106, 2012

43. Pellaprat J, Ory-Magne F, Canivet C, Simonetta-Moreau M, Lotterie JA, Radji F, et al: Deep brain stimulation of the subthalamic nucleus improves pain in Parkinson's disease. Parkinsonism Relat Disord 20:662-664, 2014

44. Quittenbaum BH, Grahn B: Quality of life and pain in Parkinson's disease: a controlled cross-sectional study. Parkinsonism Relat Disord 10:129-136, 2004

45. Ramdhani RA, Patel A, Swope D, Kopell BH: Early use of $60 \mathrm{~Hz}$ frequency subthalamic stimulation in Parkinson's disease: a case series and review. Neuromodulation 18:664669, 2015

46. Rana A, Saeed U, Masroor MS, Yousuf MS, Siddiqui I: A cross-sectional study investigating clinical predictors and physical experiences of pain in Parkinson's disease. Funct Neurol 28:297-304, 2013

47. Ricchi V, Zibetti M, Angrisano S, Merola A, Arduino N, Artusi CA, et al: Transient effects of $80 \mathrm{~Hz}$ stimulation on gait in STN DBS treated PD patients: a 15 months follow-up study. Brain Stimulat 5:388-392, 2012 
48. Saadé NE, Atweh SF, Bahuth NB, Jabbur SJ: Augmentation of nociceptive reflexes and chronic deafferentation pain by chemical lesions of either dopaminergic terminals or midbrain dopaminergic neurons. Brain Res 751:1-12, 1997

49. Schestatsky P, Kumru H, Valls-Solé J, Valldeoriola F, Marti MJ, Tolosa E, et al: Neurophysiologic study of central pain in patients with Parkinson disease. Neurology 69:2162-2169, 2007

50. Siao P, Cros DP: Quantitative sensory testing. Phys Med Rehabil Clin N Am 14:261-286, 2003

51. Sidiropoulos C, Walsh R, Meaney C, Poon YY, Fallis M, Moro E: Low-frequency subthalamic nucleus deep brain stimulation for axial symptoms in advanced Parkinson's disease. J Neurol 260:2306-2311, 2013

52. Smith H, Gee L, Kumar V, Ramirez-Zamora A, Durphy J, Hanspal E, et al: Deep brain stimulation significantly decreases disability from low back pain in patients with advanced Parkinson's disease. Stereotact Funct Neurosurg 93:206-211, 2015

53. Spielberger S, Wolf E, Kress M, Seppi K, Poewe W: The influence of deep brain stimulation on pain perception in Parkinson's disease. Mov Disord 26:1367-1369, 2011

54. Sürücü O, Baumann-Vogel H, Uhl M, Imbach LL, Baumann CR: Subthalamic deep brain stimulation versus best medical therapy for L-dopa responsive pain in Parkinson's disease. Pain 154:1477-1479, 2013

55. Tinazzi M, Del Vesco C, Fincati E, Ottaviani S, Smania N, Moretto G, et al: Pain and motor complications in Parkinson's disease. J Neurol Neurosurg Psychiatry 77:822-825, 2006

56. Toda K, Harada T: Prevalence, classification, and etiology of pain in Parkinson's disease: association between Parkinson's disease and fibromyalgia or chronic widespread pain. Tohoku J Exp Med 222:1-5, 2010

57. Uebelacker LA, Epstein-Lubow G, Lewis T, Broughton MK, Friedman JH: A survey of Parkinson's disease patients: most bothersome symptoms and coping preferences. J Parkinsons Dis 4:717-723, 2014

58. Xie T, Vigil J, MacCracken E, Gasparaitis A, Young J, Kang W, et al: Low-frequency stimulation of STN-DBS reduces aspiration and freezing of gait in patients with PD. Neurology 84:415-420, 2015

59. Zambito Marsala S, Tinazzi M, Vitaliani R, Recchia S, Fabris F, Marchini C, et al: Spontaneous pain, pain threshold, and pain tolerance in Parkinson's disease. J Neurol 258:627-633, 2011

60. Zengin-Toktas Y, Ferrier J, Durif F, Llorca PM, Authier N: Bilateral lesions of the nigrostriatal pathways are associated with chronic mechanical pain hypersensitivity in rats. Neurosci Res 76:261-264, 2013

\section{Disclosures}

Dr. Pilitsis is a consultant for Medtronic, Boston Scientific, and St. Jude; receives grant support from Jazz, Medtronic, Boston Scientific, St. Jude, TEVA Pharmaceuticals, and the NIH (No. 1R01CA166379) for non-study-related clinical or research effort; and is a consultant for and has equity in Centauri. Dr. RamirezZamora has received research grant support from Boston Scientific and Medtronic and honoraria from TEVA Pharmaceuticals.

\section{Author Contributions}

Conception and design: Pilitsis, Belasen. Acquisition of data: Pilitsis, Belasen, Yeung, Hanspal, Paiva, Durphy. Analysis and interpretation of data: Pilitsis, Belasen, Rizvi, Gee. Drafting the article: Pilitsis, Belasen, Rizvi, Gee, Yeung. Critically revising the article: Pilitsis, Belasen, Gee, Yeung, Ramirez-Zamora. Reviewed submitted version of manuscript: Pilitsis, Belasen, Rizvi, Gee, Prusik, Ramirez-Zamora, Hanspal, Paiva, Durphy, Argoff. Approved the final version of the manuscript on behalf of all authors: Pilitsis. Statistical analysis: Pilitsis, Belasen, Rizvi, Gee, Prusik. Administrative/technical/material support: Pilitsis, Gee, Prusik, Ramirez-Zamora, Hanspal, Paiva, Durphy, Argoff. Study supervision: Pilitsis, Prusik, Ramirez-Zamora.

\section{Correspondence}

Julie G. Pilitsis, AMC Neurosurgery Group, 47 New Scotland Ave., MC 10, Physicians Pavilion, 1st Fl., Albany, NY 12208. email:.jpilitsis@yahoo.com. 